\title{
Simvastatin inhibits the expression of inflammatory cytokines and cell adhesion molecules induced by LPS in human dental pulp cells
}

\author{
J. Y. Jung ${ }^{1}$, S. M. Woo ${ }^{1}$, W. J. Kim ${ }^{1,2}$, B. N. Lee ${ }^{3}$, J. E. Nör ${ }^{4}$, K. S. Min $^{5}$, C. H. Choi ${ }^{6}$, \\ J. T. Koh ${ }^{2}$, K. J. Lee ${ }^{7}$ \& Y. C. Hwang ${ }^{2,3}$ \\ ${ }^{1}$ Department of Physiology, School of Dentistry, Dental Science Research Institute, Chonnam National University, Gwangju; \\ ${ }^{2}$ Research Center for Biomineralization Disorders, Chonnam National University, Gwangju; ${ }^{3}$ Department of Conservative \\ Dentistry, School of Dentistry, Dental Science Research Institute, Chonnam National University, Gwangju, Korea; \\ ${ }^{4}$ Angiogenesis Research Laboratory, Department of Cariology, Restorative Sciences, Endodontics, School of Dentistry, University \\ of Michigan, Ann Arbor, MI, USA; ${ }^{5}$ Department of Conservative Dentistry, School of Dentistry, Chonbuk National University, \\ Jeonju; 'Department of Preventive and Public Health Dentistry, School of Dentistry, Dental Science Research Institute, \\ Chonnam National University, Gwangju; and ${ }^{7}$ Department of Convergence Medicine, Asan Institute for Life Sciences, Asan \\ Medical Center, University of Ulsan College of Medicine, Seoul, Korea
}

\begin{abstract}
Jung JY, Woo SM, Kim WJ, Lee BN, Nör JE, Min KS, Choi CH, Koh JT, Lee KJ, Hwang YC. Simvastatin inhibits the expression of inflammatory cytokines and cell adhesion molecules induced by LPS in human dental pulp cells. International Endodontic Journal, 50, 377-386, 2017.
\end{abstract}

Aim To investigate the effect of simvastatin on lipopolysaccharide (LPS)-stimulated inflammatory cytokines, cell adhesion molecules and nuclear factor$\kappa \mathrm{B}(\mathrm{NF}-\kappa \mathrm{B})$ transcription factors in human dental pulp cells (HDPCs).

Methodology The effect of LPS and simvastatin on human dental pulp cell (HDPCs) viability was measured using a 3-[4, 5-dimethylthiazol-2-yl]-2, 5 diphenyltetrazolium bromide (MTT) assay. The expression of inflammatory cytokines and cell adhesion molecules was evaluated by reverse-transcription polymerase chain reaction (RT-PCR), enzyme-linked immunosorbent assay (ELISA) and Western blot analysis. NF- $\kappa \mathrm{B}$ transcription factors were evaluated by

Correspondence: Yun-Chan Hwang, Department of Conservative Dentistry, School of Dentistry, Chonnam National University, Yong-bong ro 77, Bukgu, Gwangju, Korea (Tel.: +82-62530-5831, fax: +82-62-530-5629, e-mail: ychwang@ chonnam.ac.kr).

Ji-Yeon Jung and Su-Mi Woo contributed equally to this study.
Western blot analysis. Statistical analysis was performed with analysis of variance (ANOVA).

Results The viability of cells exposed to different concentrations of E. coli LPS, P. gingivalis LPS and simvastatin was not significantly different compared with that of control cells $(P>0.05)$. LPS significantly increased interleukin (IL)-1 $\beta \quad(P<0.05)$ and IL-6 mRNA expression $(P<0.05)$ and vascular cell adhesion molecule-1 (VCAM-1) $(P<0.05)$ and intercellular adhesion molecule-1 (ICAM-1) protein expression $(P<0.05)$ in HDPCs. Treatment with simvastatin significantly attenuated LPS-stimulated production of IL-1 $\beta$, IL-6, VCAM-1 and ICAM-1 $(P<0.05)$. Treatment with simvastatin decreased LPS-induced expression of p65 and phosphorylation of $\mathrm{I} \kappa \mathrm{B}$ and also significantly decreased the phosphorylation of p65 and IкB in the cytoplasm and the level of p65 in the nucleus $(P<0.05)$.

Conclusions Simvastatin has a suppressing effect on LPS-induced inflammatory cytokine, cell adhesion molecules and NF- $\mathrm{KB}$ transcription factors in HDPCs. Therefore, simvastatin might be a useful candidate as a pulp-capping agent in vital pulp therapy.

Keywords: cell adhesion molecules, inflammatory cytokines, lipopolysaccharide, NF-кB, simvastatin.

Received 22 April 2015; accepted 17 March 2016 


\section{Introduction}

Caries penetration into the pulp results in bacterial invasion and causes pulp inflammation (Hilton 2009) as a result of the bacterial components and by-products. Although this reaction represents a protective response, it can also be destructive. Unlike other body structures, the dental pulp is encased in a rigid hard tissue with no collateral circulation. As a result, the pulp can become inflamed, eventually leading to pulp necrosis (Massey et al. 1993, Martin 2003). When the pulp becomes irreversibly inflamed or infected, root canal treatment is necessary, and such therapy can be challenging when the morphology of the canal is complex (Vertucci 2005).

Vital pulp therapy, such as pulp capping, partial pulpotomy or full pulpotomy, is an alternative to pulpectomy and can be successful (Aguilar \& Linsuwanont 2011). Partial pulpotomy was reported to be effective in treating permanent teeth with deep carious lesions (Mass \& Zilberman 2011), and partial pulpotomy using ProRoot MTA (Dentsply Tulsa Dental, Tulsa, OK, USA) or Dycal (L.D. Caulk, Milford, DE, USA) led to favourable outcomes in patients with reversible pulpitis (Chailertvanitkul et al. 2014). Direct pulp capping is also of value in certain cases (Willershausen et al. 2011) with cariously exposed pulps as well as traumatic or mechanical pulp exposure (Matsuo et al. 1996). However, partial pulpotomy and full pulpotomy have more predictable results than direct pulp capping in permanent teeth with cariously exposed pulps (Aguilar \& Linsuwanont 2011).

For vital pulp therapy to be successful when the pulp is inflamed, the material used to cap the pulp should have an anti-inflammatory effect and should also induce mineralization to create a dentine bridge. Therefore, an ideal pulp-capping agent should suppress inflammation and induce pulp tissue mineralization during treatment for cariously exposed pulps (Komabayashi \& Zhu 2010). Previously, ketoprofen was used to inhibit dental pulp inflammation in a laboratory model (Choi et al. 2013). Ketoprofen is a nonsteroidal anti-inflammatory agent that is used on oral lesion such as pharyngitis or inflammation of the mouth in orthodontic therapy (Choi et al. 2013). Ketoprofen has been reported to inhibit the expression of inflammatory mediators in dental pulp cells stimulated with LPS (Choi et al. 2013). However, ketoprofen does not have a mineralization-inducing effect on the dental pulp (Choi et al. 2013).

Simvastatin, an HMG-CoA reductase inhibitor, has been used to reduce the risk of cardiovascular disease.
It has an excellent tolerability profile and is associated with a low risk of adverse effects (Pedersen \& Tobert 2004, Robinson 2007). Many studies have shown that simvastatin exerts an anti-inflammatory effect and it has been shown to prevent the inflammatory process induced by lipopolysaccharide (LPS) (HernandezRomero et al. 2008). Atorvastatin, another HMG-CoA reductase inhibitor, has been shown to reduce inflammation through the inhibition of nuclear factor-kappa B (NF-кB) activity (Ortego et al. 1999). In addition, simvastatin was found to have a bone formation-promoting effect in animal studies (Mundy et al. 1999). When injected subcutaneously or administered orally, simvastatin stimulated bone formation in mice calvaria and increased the volume of cancellous bone in rats (Mundy et al. 1999). Simvastatin has also been reported to promote osteoblastic differentiation and mineralization in MC-3T3-E1 cells (Maeda et al. 2001) and to promote odontoblastic differentiation in human dental pulp cells (HDPCs) (Min et al. 2010).

Therefore, although it is possible that simvastatin could suppress inflammation in dental pulps, no study has assessed the anti-inflammatory effect of simvastatin in HDPCs. The purpose of this study was to investigate whether simvastatin suppresses the expression of inflammatory cytokine and cell adhesion molecule in HDPCs. The null hypothesis tested was that there are no differences in the anti-inflammatory effect between control and simvastatin-treated groups.

\section{Material and methods}

\section{Cell isolation and culture}

HDPCs were isolated from intact, caries-free supernumerary teeth freshly extracted from healthy children from 7 to 10 years of age. All procedures were conducted after obtaining informed consent. The study protocol was approved by the internal review board of the Chonnam National University Dental Hospital (CNUDH-2013-002). Immediately after extraction, the teeth were kept in phosphate-buffered saline and were then split open. The pulp tissues were removed under sterile conditions, minced with a surgical knife and placed in $60-\mathrm{mm}$ culture dishes containing $\alpha$-minimum essential medium ( $\alpha$-MEM) (Gibco Invitrogen, Grand Island, NY, USA) supplemented with $10 \%$ foetal bovine serum (FBS), $100 \mathrm{U} \mathrm{mL}^{-1}$ of penicillin and $100 \mathrm{mg} \mathrm{mL}^{-1}$ of streptomycin in a humidified atmosphere of $5 \% \quad \mathrm{CO}_{2}$ at $37^{\circ} \mathrm{C}$. Cell passage numbers from 3 to 4 were used for the following experiment. 


\section{Cell viability assay}

Cell viability was measured using a 3-[4,5-dimethylthiazol2-yl]-2,5 diphenyltetrazo-lium bromide (MTT) assay. For the cell viability experiments, a suspension of HDPCs at a concentration of $1 \times 10^{5}$ cells per well was seeded in 48 -well plates containing $\alpha$-MEM with $10 \%$ FBS. The concentrations of Escherichia coli (E. coli) LPS (SigmaAldrich, St. Louis, MO, USA) and of Porphyromonas gingivalis (P. gingivalis) LPS (Invivogen, San Diego, CA, USA) were set at $0.1,1,10$ and $20 \mu \mathrm{g} \mathrm{mL}^{-1}$. The concentrations of simvastatin were set at $0.1,1,5$ and $10 \mu \mathrm{mol} \mathrm{L}^{-1}$. After the cells were incubated for $24 \mathrm{~h}$, MTT was added to each well for the last $4 \mathrm{~h}$ of the experiment, which was then stopped by the addition of dimethyl sulfoxide (DMSO). Optical density was determined at a 570-nm wavelength on a multiwell plate reader. Background absorbance of medium in the absence of cells was subtracted.

\section{Reverse-transcription Polymerase Chain Reaction (RT-PCR)}

The total RNA of dental pulp cells was extracted using TRIzol reagent (Life Technologies, Gaithersburg, MD, USA), according to the manufacturer's instructions. Then, $2 \mu \mathrm{g}$ of RNA was reverse-transcribed for the synthesis of first-strand complementary DNA (cDNA) (Gibco BRL, Rockville, MD, USA). The cDNA was amplified in a final volume of $20 \mu \mathrm{L}$ containing $2.5 \mathrm{mmol} \mathrm{L}^{-1}$ of magnesium dichloride, 1.25 $\mathrm{U}$ of Ex Taq Polymerase (Bioneer, Daejeon, Korea) and $1 \mathrm{mmol} \mathrm{L} \mathrm{L}^{-1}$ of specific primers. Thermocycling conditions consisted of $94{ }^{\circ} \mathrm{C}$ for $5 \mathrm{~m}$ and then 30 cycles at $94{ }^{\circ} \mathrm{C}$ for $40 \mathrm{~s}$, at $55^{\circ} \mathrm{C}$ for $40 \mathrm{~s}$ and at $72{ }^{\circ} \mathrm{C}$ for $90 \mathrm{~s}$, followed by a final $10-\mathrm{m}$ extension at $72{ }^{\circ} \mathrm{C}$. Primer sequences for PCR are described in Table 1. The PCR products were resolved on a $1.5 \%$ agarose gel and stained with ethidium bromide and visualized with a UV Transilluminator/Polaroid camera BioImaging System (UVP, LLC, Upland, CA, USA). PCR results were quantified using ImageJ software, version 1.47 (National Institutes of Health, Bethesda, MD, USA). The band density of each gene was normalized with the density of glyceraldehyde 3-phosphate dehydrogenase (GAPDH) as a control.

\section{Western blot analysis}

Cell lysates ( 50 to $100 \mu \mathrm{g}$ ) were placed in a lysis buffer $\left(30 \mathrm{~m} \mathrm{~mol} \mathrm{~L}^{-1}\right.$ of Tris-Cl $[\mathrm{pH} \quad 7.5], 1 \%$ NP-40,
$1 \mathrm{~m} \mathrm{~mol} \mathrm{~L}^{-1}$ of EDTA, $150 \mathrm{~m} \mathrm{~mol} \mathrm{~L}^{-1}$ of $\mathrm{NaCl}$, $1 \mathrm{~m} \mathrm{~mol} \mathrm{~L}{ }^{-1}$ of phenylmethanesulfonyl fluoride [PMSF] and a protease inhibitor mixture containing $1 \mu \mathrm{g} \mathrm{mL}$ of aprotinin and leupeptin), separated by $12 \%$ polyacrylamide gel electrophoresis and transferred to a nitrocellulose membrane (Santa Cruz Biotechnology, Santa Cruz, CA, USA), according to the standard procedures. The membrane was blocked in 5\% nonfat dry milk and incubated with primary antibodies for vascular cell adhesion molecule-1 (VCAM-1) and for intercellular adhesion molecule-1 (ICAM-1) (Santa Cruz Biotechnology), p65 (Abcam, Cambridge, UK), and p-IкB and IкB (Cell Signaling, Danvers, MA, USA) for $1 \mathrm{~h}$ at room temperature. After incubation with the specific peroxidasecoupled secondary antibodies (Thermo Scientific, Rockford, IL, USA) for $1 \mathrm{~h}$, the blotted bands were detected using an enhanced chemiluminescence detection kit (Amersham Pharmacia Biotech, Little Chalfort, UK).

Cells that had been incubated with $1 \mu \mathrm{g} \mathrm{mL} \mathrm{m}^{-1}$ of E. coli LPS or with $1 \mu \mathrm{g} \mathrm{mL}^{-1}$ of $P$. gingivalis LPS in the absence or presence of $5 \mu \mathrm{M}$ of simvastatin for $24 \mathrm{~h}$ were harvested. The nuclear and cytoplasmic proteins were collected by the ProteoExtract Subcellular Proteome Extraction Kit (Calbiochem, San Diego, CA, USA). Western blot assay was performed, and the nitrocellulose membrane was incubated overnight at $4{ }^{\circ} \mathrm{C}$ with primary antibodies for p-p65 (Cell Signal-

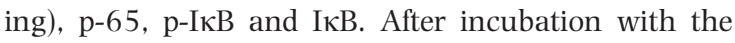
specific peroxidase-coupled secondary antibodies (Thermo Scientific) for $1 \mathrm{~h}$, the blotted bands were detected using an enhanced chemiluminescence detection kit (Amersham Pharmacia Biotech). Histone $\mathrm{H} 1$ and $\beta$-actin were used as the internal controls for the nuclear and cytoplasmic proteins, respectively.

\section{Enzyme-linked immunosorbent assay (ELISA)}

Cells were incubated with $1 \mu \mathrm{g} \mathrm{mL}^{-1}$ of E. coli LPS or with $P$. gingivalis LPS in the absence or presence of $5 \mu \mathrm{M}$ of simvastatin for $24 \mathrm{~h}$. The levels of IL- $1 \beta$ and IL-6 were determined by means of enzyme-linked immunosorbent assay (ELISA) kits (R\&D Systems Inc, Minneapolis, MN, USA). In all cases, a standard curve was constructed from the standards provided by the manufacturer. Cytokine levels were normalized to the protein concentration in lysate.

\section{Statistical analysis}

Data were analysed using one-way analysis of variance (ANOVA), followed by the Student-Newman-Keuls 
test, as compared with control. Differences for which $P$-values were less than 0.05 were considered statistically significant.

\section{Results}

Effects of LPS and simvastatin on viability of HDPCs

The effect of E. coli LPS, P. gingivalis LPS and simvastatin on cell viability of HDPCs is shown in Fig. 1. The viability of cells exposed to different concentra- tions of E. coli LPS, P. gingivalis LPS and simvastatin was not significantly different from that of the controls $(P>0.05)$.

Effects of LPS on the expression of inflammatory cytokines and cell adhesion molecules

To investigate whether E. coli LPS and P. gingivalis LPS induced an inflammatory reaction in HDPCs, the expression of interleukin (IL)-1 $\beta$ and IL-6 was assessed in LPS-treated HDPCs. As shown in Fig. 2a and 2 b, E. coli LPS and P. gingivalis LPS significantly

Table 1 Primer sequences used for RT-PCR

\begin{tabular}{|c|c|c|c|}
\hline Genes & $\begin{array}{c}\text { GenBank } \\
\text { number }\end{array}$ & Sequences $\left(5^{\prime}-3^{\prime}\right)$ & Length of product \\
\hline \multirow[t]{2}{*}{ IL-1 $\beta$} & NM_000576.2 & F: GATACAAACTGATGAAGCTCGTCA & $172 \mathrm{bp}$ \\
\hline & & R: GAGATAGTGTTTTCCACATCCTGA & \\
\hline \multirow[t]{2}{*}{ IL-6 } & NM_000600.3 & F: GAACAAGCCAGAGCTGTCCA & $230 \mathrm{bp}$ \\
\hline & & R: TGAGGTGCCCATGCTACATT & \\
\hline \multirow[t]{2}{*}{ GAPDH } & NM_001256799 & F: AGTCACGGATTT GGTCGT & $185 \mathrm{bp}$ \\
\hline & & R: ACAAGCTTCCCGTTCTCAG & \\
\hline
\end{tabular}
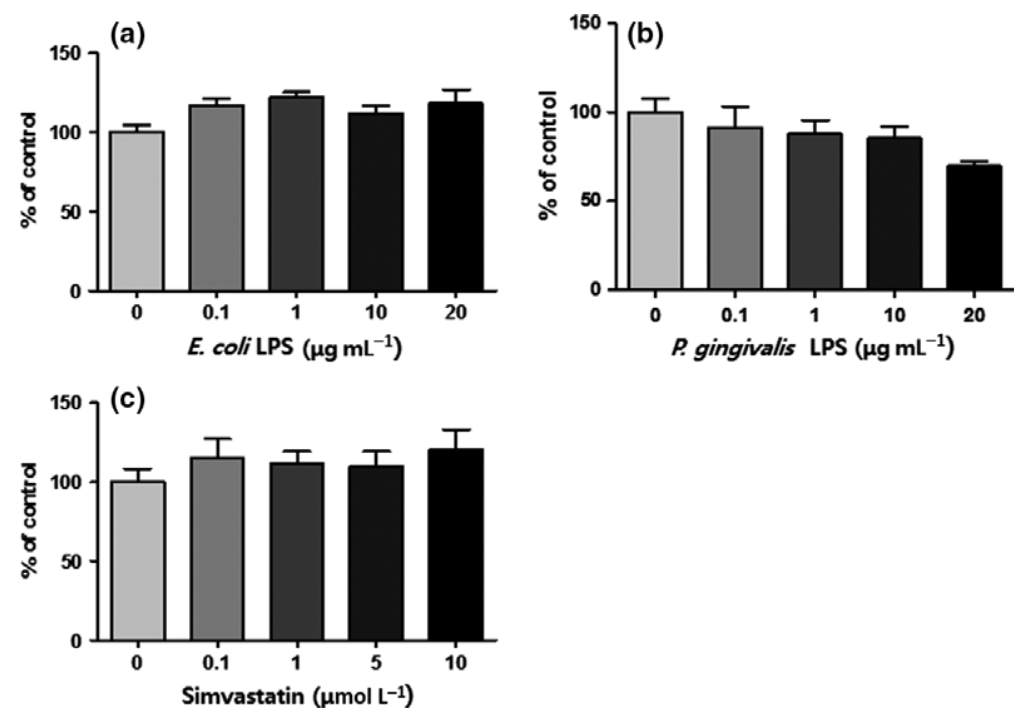

Figure 1 Effects of E. coli LPS, P. gingivalis LPS and simvastatin on cell viability of HDPCs. The MTT assay was used to assess the viability of HDPCs for $24 \mathrm{~h}$ after treatment with different concentrations of (a) E. coli LPS, (b) P. gingivalis LPS and (c) simvastatin. Values are expressed as means \pm SD of three replicates of one representative experiment.

Figure 2 Effects of LPS on the expression of IL-1 $\beta$, IL-6, VCAM-1 and ICAM-1 in HDPCs. The cells were treated with $0.1,1$ and $10 \mu \mathrm{g} \mathrm{mL}^{-1}$ of $E$. coli LPS and of $P$. gingivalis LPS for $24 \mathrm{~h}$. (a) The mRNA levels of IL-1 $\beta$ and IL- 6 were determined by RT-PCR. (b) The protein levels of IL- $1 \beta$ and IL- 6 were determined with the use of ELISA kits. (c) The protein levels of VCAM-1 and ICAM-1 were determined by means of Western blot analysis. Values are expressed as means \pm SD of three replicates of one representative experiment. ${ }^{*} P<0.05$, versus control. The data shown are representative of three independent experiments with triplicates for each experiment. 
(a)

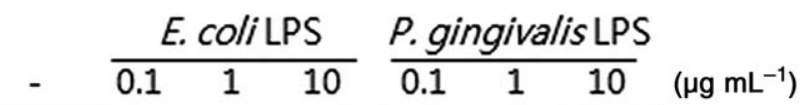

IL-1 $\beta$

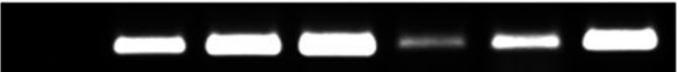

IL-6

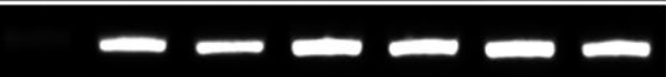

GAPDH
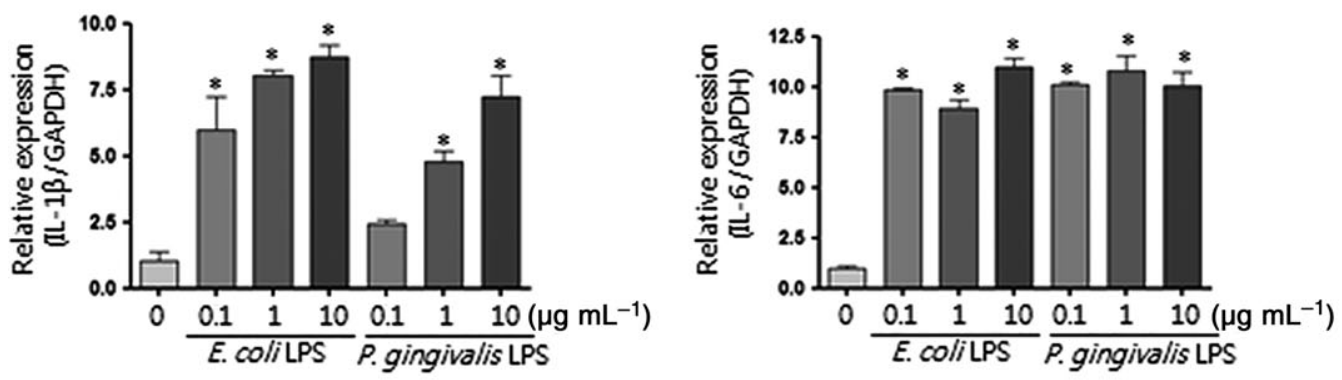

(b)
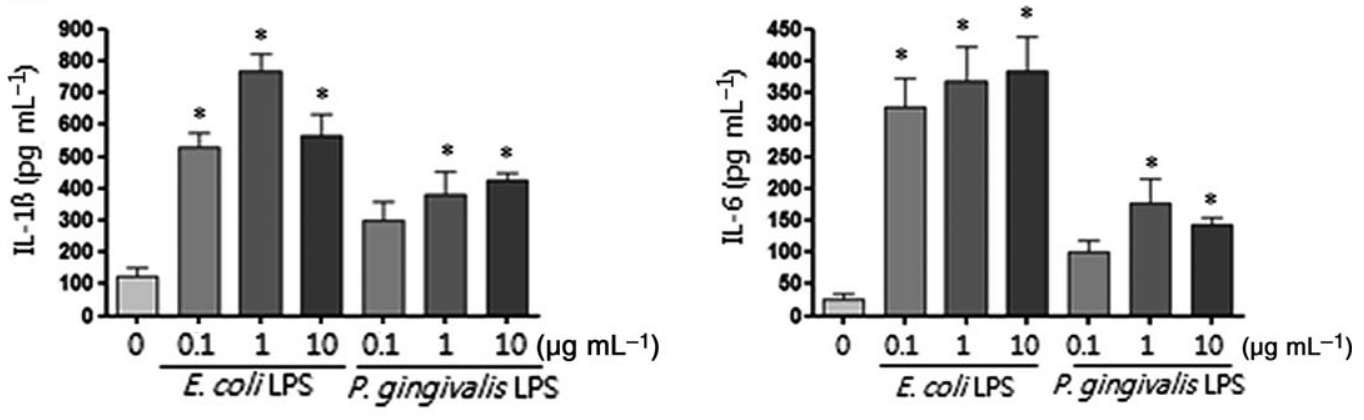

(c)
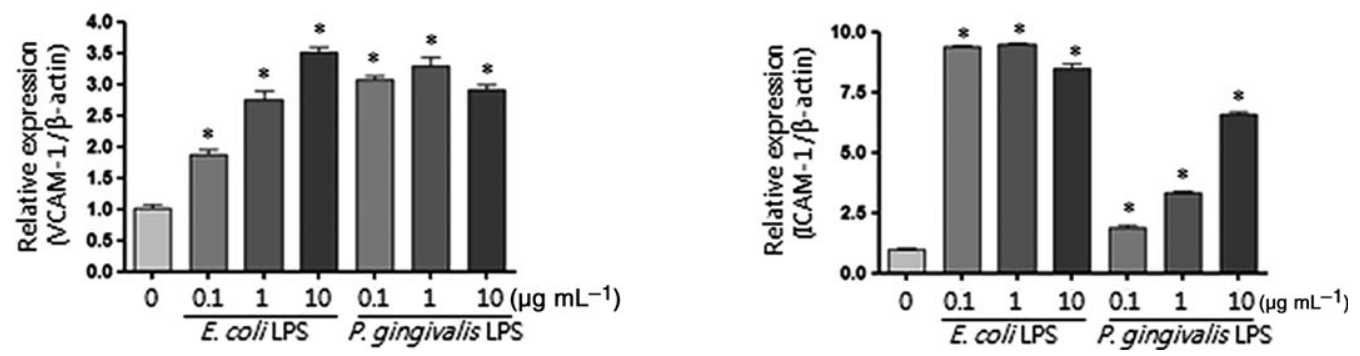
increased both IL-1 $\beta$ and IL- 6 mRNA expression and IL-1 $\beta$ and IL- 6 protein secretion. In addition, the expression of cell adhesion molecules, such as VCAM1 and ICAM-1, was upregulated after the HDPCs were treated with both types of LPS (Fig. 2c). Densitometry showed that there was a significant increment in IL$1 \beta(P<0.05)$ and IL-6 mRNA expression $(P<0.05)$ and in VCAM-1 $(P<0.05)$ and ICAM-1 expression $(P<0.05)$ after treatment with LPS, beginning at concentrations of $0.1 \mu \mathrm{g} \mathrm{mL}^{-1}$ and higher (Fig. 2).

\section{Effects of simvastatin on LPS-upregulated inflammatory cytokines and cell adhesion molecules}

To determine the effect of simvastatin on LPS-induced pulpal inflammation, the expression and secretion of cytokines such as IL-1 $\beta$ and IL- 6 and the expression of cell adhesion molecules such as VCAM-1 and ICAM-1 were examined in HDPCs stimulated with E. coli LPS or P. gingivalis LPS in the presence of simvastatin for $24 \mathrm{~h}$. Treatment with simvastatin significantly attenuated the LPS-stimulated expression of IL-1 $\beta(P<0.05)$ and IL-6 $(P<0.05)$ in HDPCs (Fig. 3a). The inhibitory effect of simvastatin on the secretion of cytokines into the supernatant was measured by ELISA. Detection of the secreted forms of IL- $1 \beta$ and IL- 6 confirmed that simvastatin blocked the increments in IL-1 $\beta(P<0.05)$ and IL-6 proteins $(P<0.05)$ in the supernatant of LPS-stimulated HDPCs (Fig. 3b). The effect of simvastatin on LPS-stimulated IL-1 $\beta$ and IL-6 protein secretion corresponded to its effect on mRNA expression. In addition, upregulated VCAM-1 and ICAM-1 production in HDPCs stimulated with LPS was inhibited by simvastatin treatment (Fig. 3c) $(P<0.05$ compared with the E. coli LPS-treated group; $P<0.05$ compared with the $P$. gingivalis LPS-treated group).

\section{Effects of simvastatin on LPS-stimulated NF-кB pathway}

To determine the mechanism involved in the response to simvastatin, the effect of simvastatin on LPS-stimulated NF- $\kappa$ B pathway was examined. Simvastatin treatment significantly decreased LPS-induced p65 expression and phosphorylation of $\mathrm{I} \kappa \mathrm{B}$ in the whole extract (Fig. 4a) $(P<0.05)$, and it also significantly decreased LPS-increased phosphorylation of p65 and I $\mathrm{B}$ in the cytoplasm and p65 level in the nucleus (Fig. 4b) $(P<0.05) \quad(P<0.05$ compared with the
E. coli LPS-treated group; $P<0.05$ compared with the $P$. gingivalis LPS-treated group).

\section{Discussion}

Caries lesions are associated with bacterial penetration of the pulp which evoke inflammation, and eventually pulp necrosis and periapical pathosis (Hilton 2009). LPS, an endotoxin of gram-negative bacteria, mediates activity of the offending organism and induces an immune response in the host cells. LPS is also involved in the development of dental pulp inflammation and pulpitis. If the pulp can recover from the inflammatory state, the inflammation is classified as reversible pulpitis. Vital pulp therapy aims to treat reversible pulpitis and recover to a normal pulp state (Ward 2002). For the success of vital pulp therapy, factors such as age, size of exposure, state of pulp, extra-pulpal blood clot and choice of capping material may affect to the outcomes (Ward 2002). Calcium hydroxide has been used as a vital pulp therapy for some time (Foreman \& Barnes 1990). MTA has been used in the direct pulp capping and pulpotomy and has been associated with good results (Chailertvanitkul et al. 2014). Anti-inflammatory agents such as corticosteroid have also been used as pulp-capping agents (Obersztyn et al. 1968).

Simvastatin has been reported to have certain pharmacological effects in various tissues and cell types, including a wide range of anti-inflammatory effects. In one study, simvastatin reduced IL-1 $\beta$, IL-6 and cyclooxygenase (COX) 2 expression in human umbilical vein endothelial cells (HUVECs) (Inoue et al. 2000), and in another report, treatment with simvastatin reduced serum levels of IL- 6 and TNF- $\alpha$ in patients with hypercholesterolaemia (Musial et al. 2001). In an experimental model of temporomandibular joint inflammation, simvastatin injected into the joint was effective in reducing subsynovial inflammation (George et al. 2013). Nevertheless, no studies have been carried out to assess the potential anti-inflammatory effect of simvastatin in human pulp cells. In the present study, simvastatin effectively decreased the expression of IL-1 $\beta$, IL- 6 , and VCAM-1 and ICAM-1 induced by LPS in HDPCs. The suppressive effect of simvastatin on inflammatory cytokines is similar to that observed in other cell types, as shown in a previous study (Inoue et al. 2000).

IL-1 $\beta$, IL- 6 and tumor necrosis factor-alpha (TNF- $\alpha$ ) are well known as key pro-inflammatory mediators in the pathogenesis of inflammatory conditions (Green- 
(a)
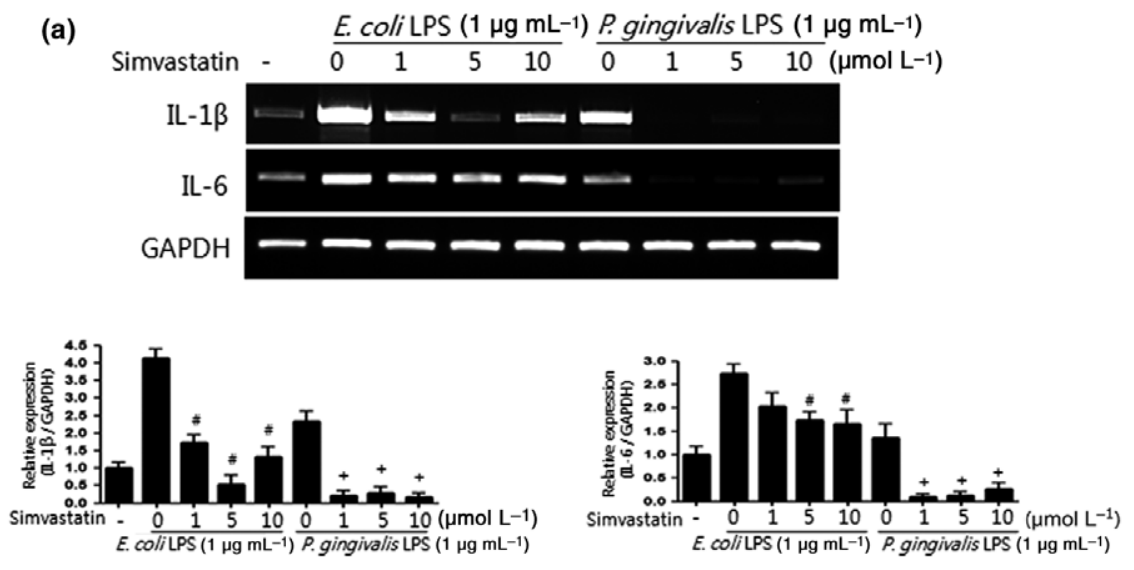

(b)

(c)
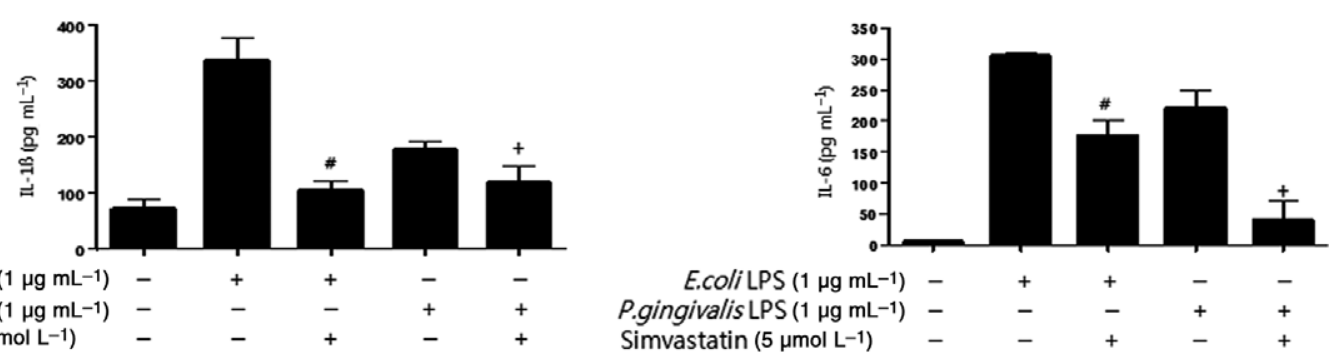

P.gingivalis LPS $(1 \mu \mathrm{g} \mathrm{mL}-1)$ Simvastatin $(5 \mu \mathrm{mol} \mathrm{L}-1)$
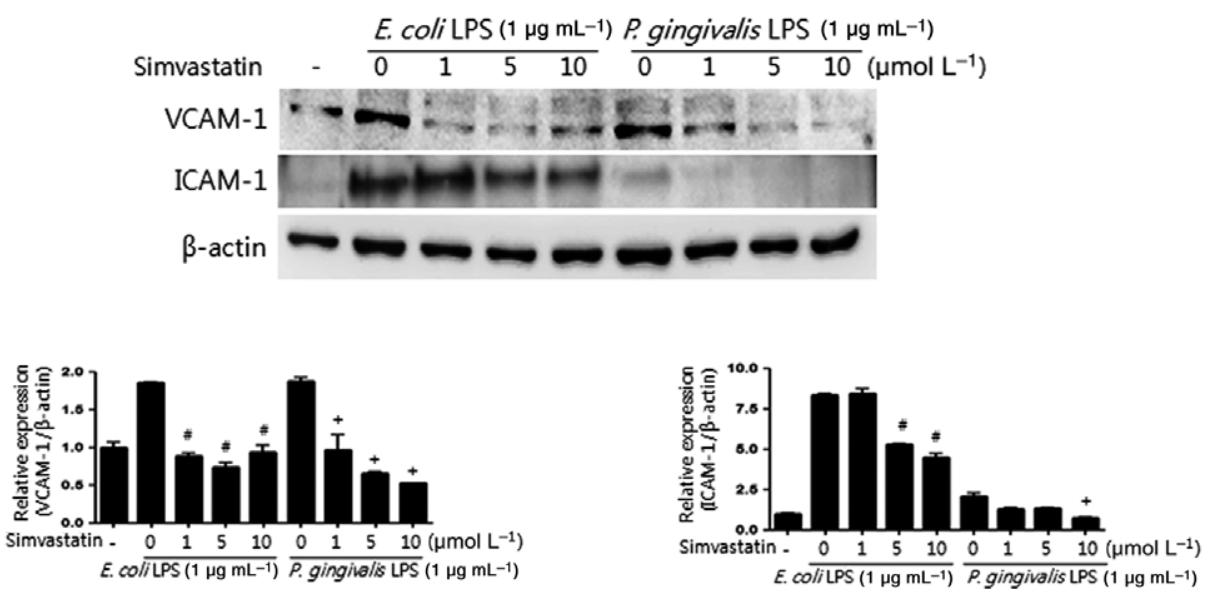

Figure 3 Effects of simvastatin on the expression of IL- $1 \beta$ and IL- 6 and VCAM- 1 and ICAM- 1 expression induced by E. coli LPS and P. gingivalis LPS in HDPCs. Cells were cultured with or without $1 \mu \mathrm{g} \mathrm{mL} \mathrm{L}^{-1}$ of $E$. coli LPS or of $P$. gingivalis LPS for $24 \mathrm{~h}$ with the concentrations of simvastatin as indicated. (a) The mRNA levels of IL-1 $\beta$ and IL-6 were determined by RT-PCR. (b) The protein levels of IL- $1 \beta$ and IL- 6 were determined using ELISA kits. (c) The protein levels of VCAM- 1 and ICAM-1 were determined by means of Western blot analysis. Values are expressed as means \pm SD of three replicates of one representative experiment. The data shown are representative of three independent experiments with triplicates for each experiment. ${ }^{\#} P<0.05$, versus the $E$. coli LPS-treated group; ${ }^{+} P<0.05$, versus the $P$. gingivalis LPS-treated group.

hill et al. 2011, Tang et al. 2015), and LPS induces the expression of many inflammatory cytokines, such as IL-1 $\beta$, IL-6, IL- 8 and TNF- $\alpha$, in HDPCs (Coli et al. 2004, Nakanishi et al. 2010, Choi et al. 2013, Kim et al. 2015).
ICAM-1 and VCAM-1, which belong to the immunoglobulin superfamily of cell adhesion molecules, are thought to regulate the attachment and migration of leucocytes during the inflammatory process (Blake \& Ridker 2001). It has been reported that 
(a)
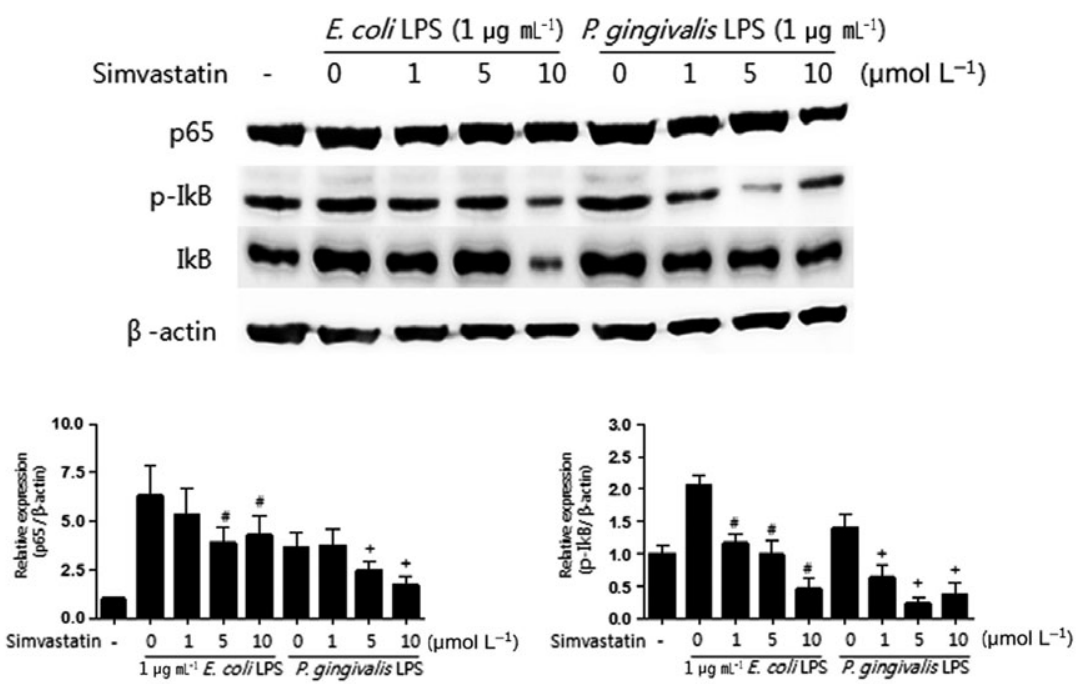

(b)
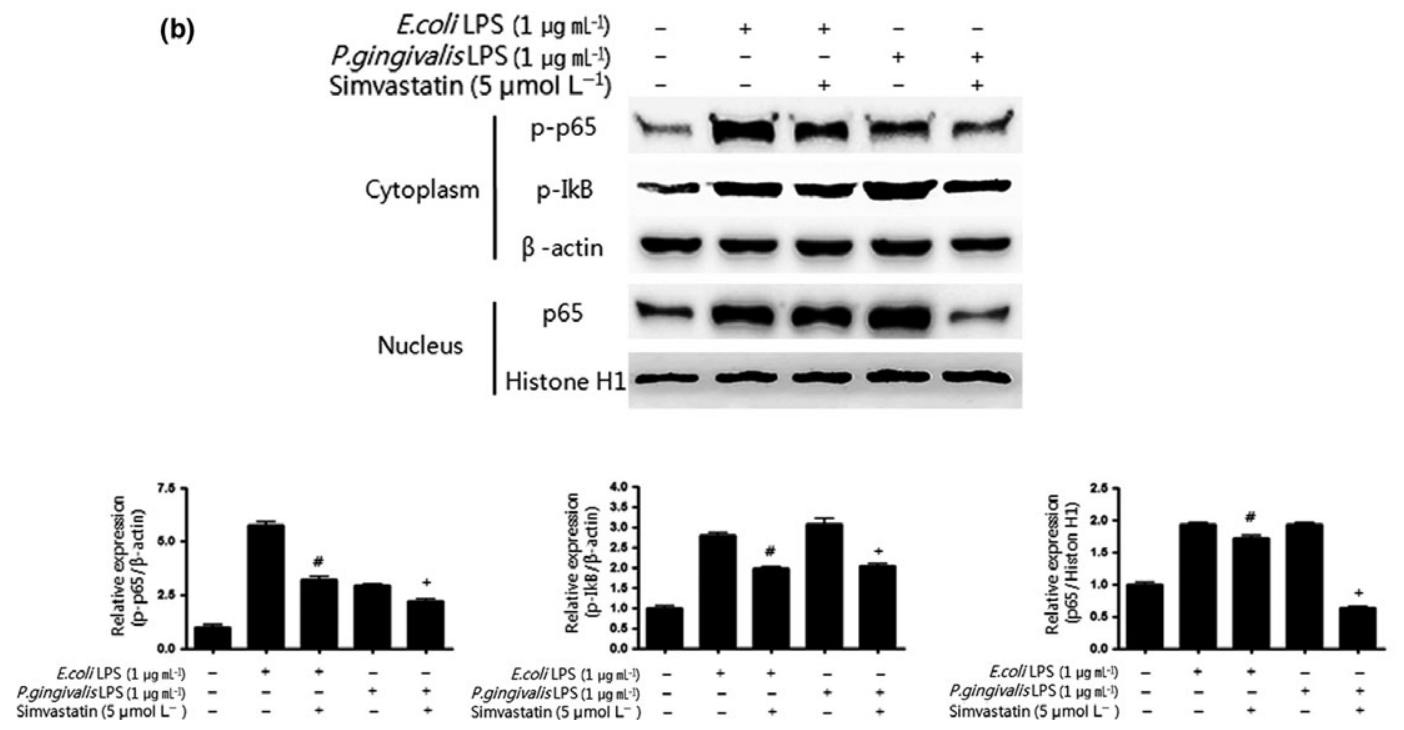

Figure 4 Effects of simvastatin on the NF-кB pathway in HDPCs. Cells were cultured with or without $1 \mu \mathrm{g} \mathrm{mL} \mathrm{L}^{-1}$ E. coli LPS or P. gingivalis LPS for $24 \mathrm{~h}$ with the concentrations of simvastatin as indicated. (a) The protein expression of p65, phospho-IкB and IкB was determined by means of Western blot analysis. (b) Protein levels of phospho-p65 and phospho-IкB in the cytoplasm and p65 in the nucleus of HDPCs were assessed. Values are expressed as means \pm SD of three replicates of one representative experiment. The data shown are representative of three independent experiments with triplicates for each experiment. ${ }^{\#} P<0.05$, versus the E. coli LPS-treated group; ${ }^{+} P<0.05$, versus the $P$. gingivalis LPS-treated group.

these molecules are expressed in inflamed human dental pulps and actually enhance pulp inflammation (Sawa et al. 1998). Because bacterial components such as LPS can induce ICAM-1 and VCAM-1 expression in dental pulp cells (Lee et al. 2008, Nakanishi et al. 2010), IL-1 $\beta$, IL-6, and ICAM-1 and VCAM-1 were used as markers of inflammation induction. LPS increased the expression of these inflammatory cytokines in the HDPCs. This finding is in accordance with results reported by others (Coli et al. 2004, Lee et al. 2008, Choi et al. 2013).

$\mathrm{NF}-\kappa \mathrm{B}$ is a transcription factor that binds to the enhancer element of the immunoglobulin kappa light chain of activated B cells (Hoesel \& Schmid 2013). In addition, the NF- $\mathrm{KB}$ pathway is known to be a key mediator of genes involved in controlling cellular proliferation and apoptosis. Therefore, NF- $\mathrm{B}$ has an important role in regulating cellular proliferation, and 
activation of NF- $\mathrm{BB}$ can reduce apoptosis (Hoesel \& Schmid 2013).

$\mathrm{NF}-\mathrm{\kappa B}$ transcription factor also plays an essential role in the regulation of inflammation and the immune response. Inflammatory processes are associated with activation of the NF- $\mathrm{BB}$ signalling pathway (Hoesel \& Schmid 2013), so inhibition of this pathway could have a potential role in reducing inflammation (Yamamoto \& Gaynor 2001). Several transduction cascades mediate stimulation of the NF$\kappa \mathrm{B}$ pathway. Activation of $\mathrm{I} \kappa \mathrm{B}$ kinase causes phosphorylation of $\mathrm{I} \kappa \mathrm{B}$, leading to its ubiquitination and degradation. Degradation of I $\mathrm{I} B$ results in the translocation of NF- $\kappa \mathrm{B}$ from the cytoplasm to the nucleus where it induces the expression of specific cellular genes (Yamamoto \& Gaynor 2001).

To demonstrate the mechanism of simvastatin that inhibits inflammatory cytokine expression, this study examined the effect of simvastatin on the NF- $\mathrm{BB}$ pathway. Simvastatin decreased the phosphorylation of I $\kappa \mathrm{B}$ and p65 in the nucleus, which had been increased by LPS. Based on these results, the suppressive effect of simvastatin on LPS-induced inflammatory cytokines in HDPCs seems to be related to inhibition of the NF$\kappa \mathrm{B}$ pathway. This finding is consistent with a previous study of epidermal burn injury in mice showing that simvastatin reduced inflammatory cytokine production and apoptosis via downregulation of the TNF- $\alpha$ / NF-кB pathway (Zhao et al. 2015).

Asl Aminabadi et al. (2013) assessed the use of simvastatin versus calcium hydroxide as a pulp-capping agent, but the anti-inflammatory effect of simvastatin was controversial. It is possible that their result was related to the experimental design in that they studied the pulp in its normal state. Under such normal conditions, implantation materials can cause an inflammatory response (Jegat et al. 2007). However, in the present study, LPS activated the inflammatory cytokines, which were reduced by treatment with simvastatin. Moreover, in the study by Asl Aminabadi et al. (2013) sodium carboxymethyl cellulose was used as a carrier of simvastatin, and cellulose derivatives can be degraded by bacteria (Reese et al. 1950). For the clinical application of simvastatin in inflammatory conditions, a nondegradable carrier, such as bioglass, would have been more appropriate.

\section{Conclusion}

Simvastatin had an anti-inflammatory effect on LPS-induced inflammation in HDPCs. Therefore, simvastatin might be a useful candidate as a pulpcapping agent in vital pulp therapy.

\section{Acknowledgements}

This study was supported by the National Research Foundation of Korea grant funded by the Korea government (MSIP) (No. 2011-0030121) and supported by the National Research Foundation of Korea (NRF) grant funded by the Korea government (MSIP) (2015R1A2A2A01006595) and supported by the grant (CRI 14040-21) Chonnam National University Hospital Research Institute of clinical medicine.

\section{Conflict of interest}

The authors have stated explicitly that there are no conflicts of interest in connection with this article.

\section{References}

Aguilar P, Linsuwanont P (2011) Vital pulp therapy in vital permanent teeth with cariously exposed pulp: a systematic review. Journal of Endodontics 37, 581-7.

Asl Aminabadi N, Maljaei E, Erfanparast L, Ala Aqhbli A, Hamishehkar H, Najafpuor E (2013) Simvastatin versus calcium hydroxide direct pulp capping of human primary molars: A randomized clinical trial. Journal of Dental Research, Dental Clinic, Dental Prospects 7, 8-14.

Blake GJ, Ridker PM (2001) Novel clinical markers of vascular wall inflammation. Circulation Research 89, 76371.

Chailertvanitkul P, Paphangkorakit J, Sooksantisakoonchai $\mathrm{N}$ et al. (2014) Randomized controlled trial comparing calcium hydroxide and mineral trioxide aggregate for partial pulpotomies in cariously exposed pulps of permanent molars. International Endodontic Journal 47, 835-42.

Choi EK, Kim SH, Kang IC et al. (2013) Ketoprofen inhibits expression of inflammatory mediators in human dental pulp cells. Journal of Endodontics 39, 764-7.

Coli J, Tam E, Waterfield JD (2004) Proinflammatory cytokine profiles in pulp fibroblasts stimulated with lipopolysaccharide and methyl mercaptan. Journal of Endodontics 30, 88-91.

Foreman PC, Barnes IE (1990) A review of calcium hydroxide. International Endodontic Journal 23, 283-97.

George MD, Owen CM, Reinhardt AL, Giannini PJ, Marx DB, Reinhardt RA (2013) Effect of simvastatin injections on temporomandibular joint inflammation in growing rats. Journal of Oral and Maxillofacial Surgery 71, 84653.

Greenhill CJ, Rose-John S, Lissilaa R et al. (2011) IL-6 trans-signaling modulates TLR4-dependent inflammatory responses via STAT3. Journal of Immunology 186, 1199-208. 
Hernandez-Romero MC, Arguelles S, Villaran RF et al. (2008) Simvastatin prevents the inflammatory process and the dopaminergic degeneration induced by the intranigral injection of lipopolysaccharide. Journal of Neurochemistry 105, 445-59.

Hilton TJ (2009) Keys to clinical success with pulp capping: a review of the literature. Operative Dentistry 34, 615-25.

Hoesel B, Schmid JA (2013) The complexity of NF-кB signaling in inflammation and cancer. Molecular Cancer 12, 86.

Inoue I, Goto S, Mizotani K et al. (2000) Lipophilic HMGCoA reductase inhibitor has an anti-inflammatory effect: reduction of mRNA levels for interleukin-1beta, interleukin-6, cyclooxygenase-2, and p22phox by regulation of peroxisome proliferator-activated receptor alpha (PPARalpha) in primary endothelial cells. Life Science 67, 863-76.

Jegat N, Septier D, Veis A, Poliad A, Goldberg M (2007) Short-term effects of amelogenin gene splice products $A+4$ and A- implanted in the exposed rat molar pulp. Head $\mathcal{E}$ Face Medicine 21, 40.

Kim DS, Shin MR, Kim YS et al. (2015) Anti-inflammatory effects of glutamine on LPS-stimulated human dental pulp cells correlate with activation of MKP-1 and attenuation of the MAPK and NF- $\mathrm{\kappa B}$ pathways. International Endodontic Journal 48, 220-8.

Komabayashi T, Zhu Q (2010) Innovative endodontic therapy for anti-inflammatory direct pulp capping of permanent teeth with a mature apex. Oral Surgery, Oral Medicine, Oral Pathology, Oral Radiology, and Endodontics 109, e75-81.

Lee JC, Yu MK, Lee R et al. (2008) Terrein reduces pulpal inflammation in human dental pulp cells. Journal of Endodontics 34, 433-7.

Maeda T, Matsunuma A, Kawane T, Horiuchi N (2001) Simvastatin promotes osteoblast differentiation and mineralization in MC3T3-E1 cells. Biochemical and Biophysical Research Communications 280, 874-7.

Martin FE (2003) Carious pulpitis: microbiological and histopathological considerations. Australian Endodontic Journal 29, 134-7.

Mass E, Zilberman U (2011) Long-term radiologic pulp evaluation after partial pulpotomy in young permanent molars. Quintessence International 42, 547-54.

Massey WL, Romberg DM, Hunter N, Hume WR (1993) The association of carious dentin microflora with tissue changes in human pulpitis. Oral Microbiology and Immunology $\mathbf{8}, 30-5$.

Matsuo T, Nakanishi T, Shimizu H, Ebisu S (1996) A clinical study of direct pulp capping applied to carious-exposed pulps. Journal of Endodontics 22, 551-6.

Min KS, Lee YM, Hong SO, Kim EC (2010) Simvastatin promotes odontoblastic differentiation and expression of angiogenic factors via heme oxygenase- 1 in primary cultured human dental pulp cells. Journal of Endodontics 36, 447-52.
Mundy G, Garrett R, Harris S et al. (1999) Stimulation of bone formation in vitro and in rodents by statins. Science 286, 1946-9.

Musial J, Undas A, Gajewski P, Jankowske M, Sydor W, Szczeklik A (2001) Anti-inflammatory effects of simvastatin in subjects with hypercholesterolemia. International Journal of Cardiology 77, 247-53.

Nakanishi T, Mukai K, Yumoto H, Hirao K, Hosokawa Y, Matsuo T (2010) Anti-inflammatory effect of catechin on cultured human dental pulp cells affected by bacteriaderived factors. European Journal of Oral Science 118, 14550 .

Obersztyn A, Jedrzejczyk J, Smiechowska W (1968) Application of lyophilized dentin chips, mixed with prednisolone and neomycin, on infected rat incisor pulp. Journal of Dental Research 47, 374-80.

Ortego M, Bustos C, Hernandez-Presa MA et al. (1999) Atorvastatin reduces NF-kappaB activation and chemokine expression in vascular smooth muscle cells and mononuclear cells. Atherosclerosis 147, 253-61.

Pedersen TR, Tobert JA (2004) Simvastatin: a review. Expert Opinion on Pharmacotherapy 5, 2583-96.

Reese ET, Siu RG, Levinson HS (1950) The biological degradation of soluble cellulose derivatives and its relationship to the mechanism of cellulose hydrolysis. Journal of Bacteriology 59, 485-97.

Robinson JG (2007) Simvastatin: present and future perspectives. Expert Opinion on Pharmacotherapy 8, 2159-72.

Sawa Y, Yoshida S, Shibata KI, Suzuki M, Mukaida A (1998) Vascular endothelium of human dental pulp expresses diverse adhesion molecules for leukocyte emigration. Tissue and Cell 30, 281-91.

Tang J, Luo K, Li Y et al. (2015) Capsaicin attenuates LPSinduced inflammatory cytokine production by upregulation of LXR $\alpha$. International Immunopharmacology 28, 2649.

Vertucci FJ (2005) Root canal morphology and its relationship to endodontic procedures. Endodontic Topics 10, 3-29.

Ward J (2002) Vital pulp therapy in cariously exposed permanent teeth and its limitations. Australian Endodontic Journal 28, 29-37.

Willershausen B, Willershausen I, Ross A, Velikonja S, Kasaj A, Blettner M (2011) Retrospective study on direct pulp capping with calcium hydroxide. Quintessence International 42, 165-71.

Yamamoto Y, Gaynor RB (2001) Therapeutic potential of inhibition of the NF-kappaB pathway in the treatment of inflammation and cancer. Journal of Clinical Investigation 107, 135-42.

Zhao G, Yu YM, Kaneki M, Bonab AA, Tompkins RG, Fishman AJ (2015) Simvastatin reduces burn injury-induced splenic apoptosis via downregulation of the TNF- $\alpha / \mathrm{NF}-\mathrm{\kappa B}$ pathway. Annals of Surgery 261, 1006-12. 